\title{
Ultrasonographic Signs of Poor Pregnancy Outcome
}

\author{
1'Lucía Serrano-González, ${ }^{2}$ María Martinez-Moya, ${ }^{3}$ María Platero-Mihi, ${ }^{4}$ José Bajo-Arenas, ${ }^{5}$ Tirso Perez-Medina
}

\begin{abstract}
The frequency of spontaneous abortion, when it is considered from its very beginning, along with the theoretical knowledge of the causes of the abortion, should provide a perspective to the obstetrician that, performing a sonographic exploration finds discoveries that cannot correspond to those characterizing a normal pregnancy.

The precocity of the realization of sonographic explorations in the pregnancy will allow diagnosis of many more cases of spontaneous interruptions of the development of pregnancy.

New sonographic imaging techniques including threedimensional (3D) sonography can provide additional information regarding the presence of structural anomalies via 3D volume acquisition, like craniofacial deformities, clefts, neural tube defects, abdominal wall defects, and caudal regression syndrome. It may give further details regarding the timing of embryonic/ fetal demise in early pregnancy. Sufficient informational value is regularly obtained in cases having a crown-rump length $>8 \mathrm{~mm}$.
\end{abstract}

Keywords: Abortion, Doppler ultrasonography, Missed abortion, Transvaginal ultrasonography.

How to cite this article: Serrano-González L, Martinez-Moya M, Platero-Mihi M, Bajo-Arenas J, Perez-Medina T. Ultrasonographic Signs of Poor Pregnancy Outcome. Donald School J Ultrasound Obstet Gynecol 2017;11(1):44-58.

Source of support: Nil

Conflict of interest: None

\section{INTRODUCTION}

The availability of high-resolution sonographic instrumentation allows, more precisely, to emit precise diagnosis. The decision of informing the patient about performed sonographic exploration corresponding to an interrupted pregnancy or embryonic demise represents a challenge as much for the expert sonographer as for the less experienced ones.

As a sonographer becomes more experienced with the scanner, an unviable pregnancy can be confirmed easily. It is not reasonable to give a diagnosis of abortion if doubts exist in this respect, when most of the patients

\footnotetext{
${ }^{1-3}$ Specialist, ${ }^{4,5}$ Professor

1-3Department of Obstetrics and Gynecology, Puerta de Hierro University Hospital, Madrid, Spain

${ }^{4,5}$ Department of Obstetrics and Gynecology, Autónoma University of Madrid, Spain

Corresponding Author: Tirso Perez-Medina, Professor Department of Obstetrics and Gynecology, Autónoma University of Madrid, Spain, e-mail: tperezm@sego.es
}

can wait without risking their health. Nonetheless, it is good practice to write the diagnosis of suspicion in the clinical history to avoid unpleasant situations in the following sonographic exploration. It is preferable to repeat the scan a few days later to inform the pregnancy as "not viable" if the diagnosis is not absolutely clear. Whenever doubts exist, and when the clinical situation allows it, is preferable to perform a second sonographic exploration a few days later to confirm the diagnosis.

The problems for the sonographers, especially the less experienced ones, begin when they are expected to reach a definitive conclusion before a first sonographic exploration in which the discoveries do not correspond exactly to the expected function of the date of the last menstrual period (LMP). It should be interpreted as if it is an unviable pregnancy or an abortion. Some of the data that can be obtained will help to make a diagnosis, and in other situations, already in this first sonographic exploration, there should exist enough information to reach a definitive diagnosis, i.e., to say, that which does not require confirmation with a posterior sonographic exploration. Repetition of the sonographic exploration, 7 to 10 days later, should allow, in most of the cases, to reach a definitive diagnosis.

\section{SPONTANEOUS ARREST OF THE DEVELOPMENT OF THE CONCEPTION'S PRODUCT, FREQUENCY OF SPONTANEOUS ABORTION, AND CAUSES OF ABORTION}

The frequency of spontaneous interruptions of the development of the reproductive process is very high, mainly when it is considered in the initial stages. It is calculated that considering the shortcoming of the fecundation, of each 100 potential pregnancies, only 31 will arrive to term with a live fetus. ${ }^{1,2}$ The frequency of the abortion, considering this as the spontaneous interruption of the pregnancy before the fetus has reached viability, depends therefore, on the approach that we use to define that pregnancy exists. When only considering the pregnancies reaching implantation (biochemical pregnancy), the abortion frequency is from 30 to $40 \% .{ }^{3,4}$ Based on the clinical diagnosis of pregnancy, the frequency decreases to 10 to $15 \%$. If the pregnancy progresses until reaching the 12th week, the probability of abortion decreases to 3 to $4 \%$. When the embryo is alive in the 12 th week, the abortion rate until the 20th week is only $2 \%{ }^{5}$ Rempen, ${ }^{6}$ who found heartbeat between the 5 th and 13 th week, communicates 
a rate of abortion of $8.6 \%$. When the heartbeat has been detected before the 9th week, the group presents an increasing rate of abortions, i.e., $12.5 \%$. If the patient is 35 years or older, the frequency ascends to $15.5 \%$, and if vaginal bleeding exists, to $16.3 \%$.

Siddiqi et $\mathrm{al}^{7}$ report that in pregnancies under 12 weeks, the controls have $5.2 \%$ of abortions, while the cases that presented with bleeding had an abortion rate of $16.4 \%$. Also, when patients are older than 34 years, the frequency ascends to $11.1 \%$, in comparison with those patients under 35 years, with only $4.4 \%$. Levi et $\mathrm{al}^{8}$ find a $24 \%$ rate of abortions when positive heartbeat exists, but the embryo has a crown-rump length (CRL) smaller than $5 \mathrm{~mm}$.

Goldstein ${ }^{9}$ presents his data with great clinical applicability, allowing to know the probability of abortion as a function of the sonographic findings, as shown in Table 1.

The embryonic and fetal causes, basically chromosomic anomalies, are the most frequent causes of abortion. ${ }^{10}$ The different rates reported depend on the approaches used (if only clinical pregnancies are considered). In the first weeks, they can overcome 80 to $90 \%$ of the cases. Above the 12th week, the chromosomic anomalies and the malformations are less relevant, although they continue being an important cause. From this moment on, the maternal and environmental causes acquire more importance.

New sonographic imaging techniques including threedimensional (3D) volumetry can provide additional information regarding the presence of structural anomalies via 3D volume acquisition, like craniofacial deformities, clefts, neural tube defects, abdominal wall defects, and caudal regression syndrome. It may give further details regarding the timing of embryonic/fetal demise in early pregnancy. Sufficient informational value is regularly obtained in cases having a CRL $>8 \mathrm{~mm} .^{11}$

The frequency of the spontaneous abortion, when it is considered from their very beginning, along with the theoretical knowledge of the causes of the abortion, should provide a perspective to the obstetrician that, performing a sonographic exploration finds discoveries that cannot correspond to those characterizing a normal pregnancy. The precocity of the realization of sonographic explorations in the pregnancy will allow to diagnose

Table 1: Probability of spontaneous abortion based on sonographic findings ${ }^{9}$

\begin{tabular}{ll}
\hline Structure visualized & Probability of abortion \\
\hline Gestational sac & $11.5 \%$ \\
Yolk sac & $8.5 \%$ \\
Embryo CRL $<5 \mathrm{~mm}$ & $7.2 \%$ \\
Embryo CRL $6-10 \mathrm{~mm}$ & $3.3 \%$ \\
Embryo CRL $>10 \mathrm{~mm}$ & $0.5 \%$ \\
\hline
\end{tabular}

many more cases of spontaneous interruptions of the development of pregnancy.

\section{NORMAL DEVELOPMENT IN THE FIRST TRIMESTER OF PREGNANCY}

Knowing the chronology of appearance of the visible embryonic structures using sonography and its variations is relevant to know if the pregnancy is evolving correctly.

When findings that do not correspond to the gestational age are detected, the first thing to do should be to value the probability that an error exists in the LMP or that ovulation has not been in the 14th day of the cycle. In this situation, when the embryo is alive (positive heartbeat), in most of the cases, the only responsibility is to correctly date the pregnancy. In function of the discoveries of the CRL, the LMP is calculated for sonography, the date of the conception, and the probable date of the childbirth. This is especially true when the pregnancy is of more time than the corresponding LMP indicated by the patient. When the data of the sonographic exploration correspond to pregnancy of less time, i.e., to say, retarded ovulation, the approach is different, since the fact of finding a smaller embryo than the one expected already supposes a risk factor for poor pregnancy outcome.

A useful adjunct to ultrasonography is the plasmatic determination of the $\beta$-human chorionic gonadotropic $(\beta-\mathrm{hCG})$ hormone $(\mathrm{mIU} / \mathrm{mL})$ between the 4 th and 8 th weeks of pregnancy. This determination is, among all those that can be performed in this period, the one that indicates that better clinical diffusion has been obtained. Its behavior, although with wide variations from one pregnancy to other, presents some peculiarities that make it very useful in concrete cases. The normal course pregnancies duplicate the figures in a period from 2 to 3 days, while abnormal pregnancies (ectopic or interrupted) usually show figures of irregular ascent or, even, descent. The simultaneity of the biochemical and sonographic data permit to outline a useful perspective to know the expected outcome in normal pregnancies. Essentially, it is necessary to know the $\beta$-hCG system of measure performed in each laboratory. It has been studied that the discriminatory $\beta$-hCG levels at which structures would be predicted to be seen $99 \%$ of the time were 3510,17716 , and $47685 \mathrm{mIU} / \mathrm{mL}$ for gestational sac, yolk sac, and fetal pole respectively. As we can see, these levels of serum $\beta$-hCG levels are higher than values currently used in practice. ${ }^{12}$

Based on the sonographic capacity of prediction of the actual gestational age of different structures as the diameter of the gestational sac, the yolk sac, and the CRL with a margin of 1 week, the diameter and growth of each structure with the interval of confidence from the moment of the appearance are reflected in many tables by different 


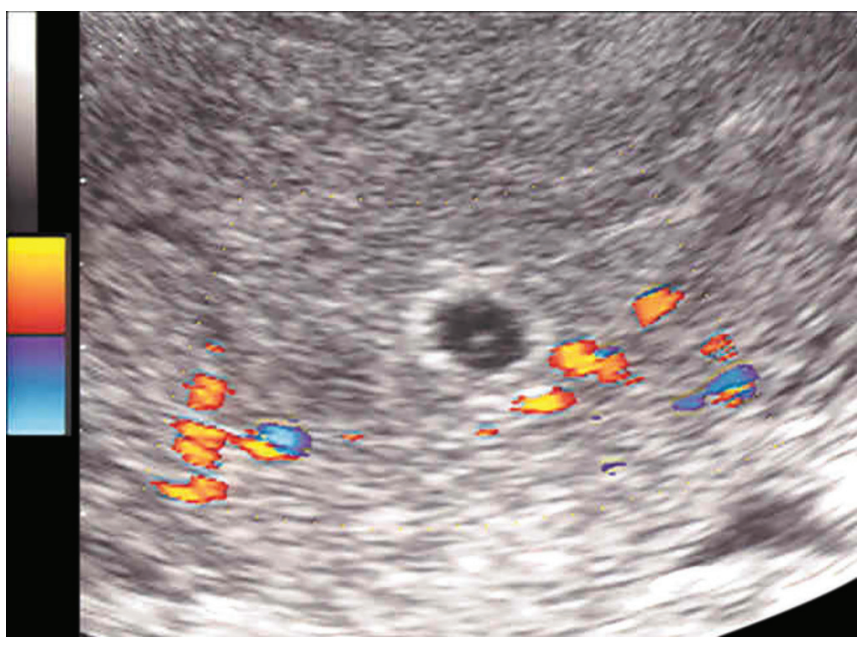

Fig. 1: Gestational sacs from 3-4 mm of diameter can usually be seen

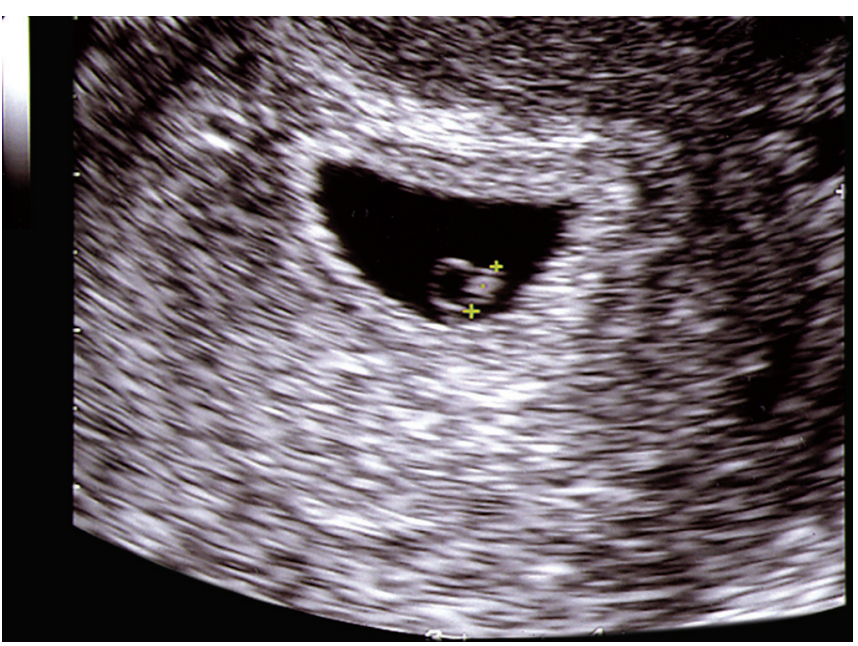

Fig. 3: A 2-4 mm CRL embryo must be seen

authors. Generally, gestational sacs of diameter of 3 to $4 \mathrm{~mm}$ on average can usually be seen (Fig. 1), with yolk sacs of 2 to $3 \mathrm{~mm}$ (Fig. 2) and embryos with CRL of 2 to $4 \mathrm{~mm}$ (Fig. 3). The amniotic vesicle is usually identified at the same time as the yolk sac (Fig. 4). The heart motion can be detected in most of the cases starting from a CRL of 3 to $4 \mathrm{~mm}$ (Fig. 5), being frequently detected before the embryonic echoes. Goldstein ${ }^{13}$ indicates that the heartbeat is even present in the embryo a few days before we are able to detect it with sonographic exploration.

All the exposed data correspond to what is possible to visualize in each moment in normal pregnancies in patients in whom conception took place 14 days after the LMP. The normal pregnancies that have begun before or after this moment will have a difference with regard to the prospective findings, but the rhythm of change among successive sonographic explorations will be the same described, so, after two sonographic explorations with at least 1 week of difference, starting from the moment in which it has been visualized as minimum, a gestational sac of 5 to $10 \mathrm{~mm}$ of diameter,

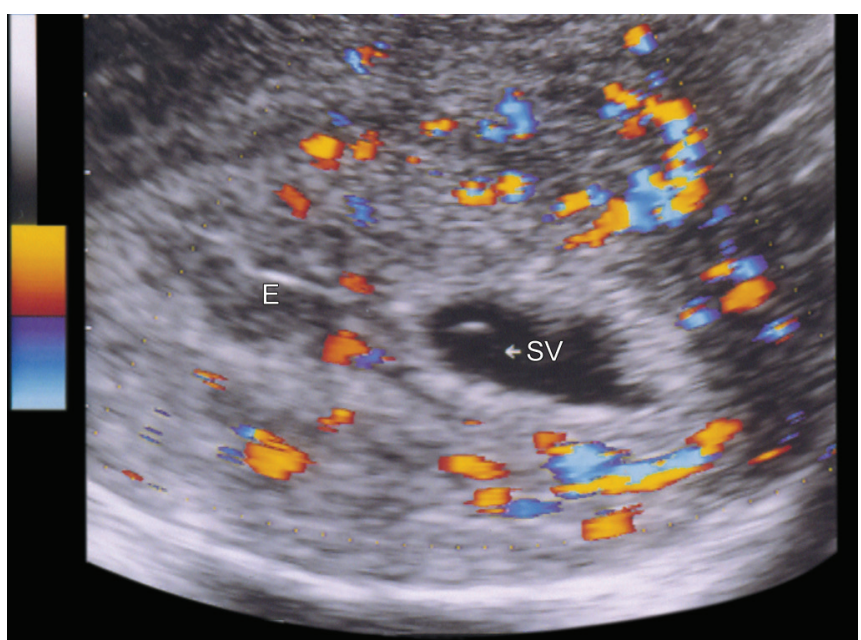

Fig. 2: The yolk sac can be seen when reaches 2-3 mm

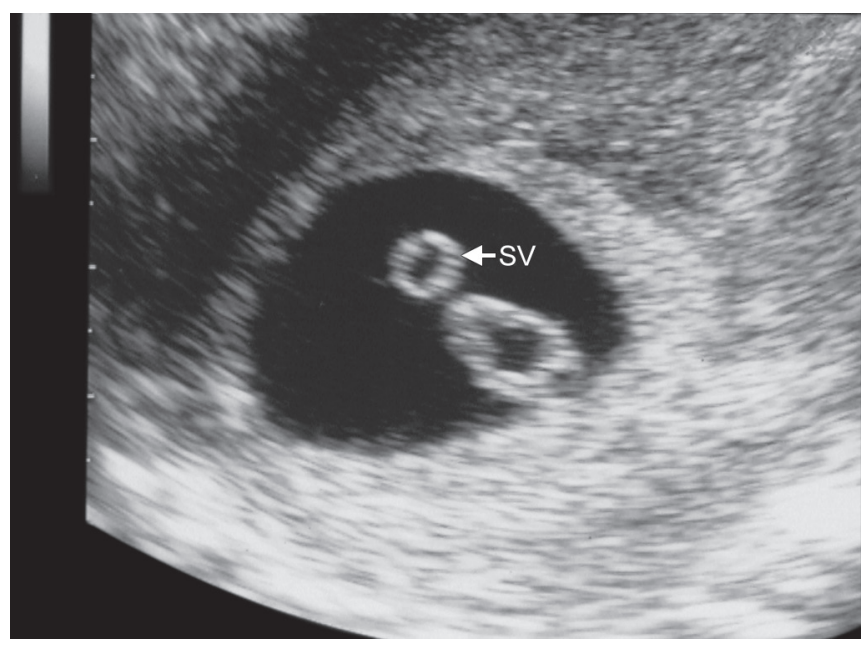

Fig. 4: The amniotic vesicle is usually observed at the same time that the yolk sac

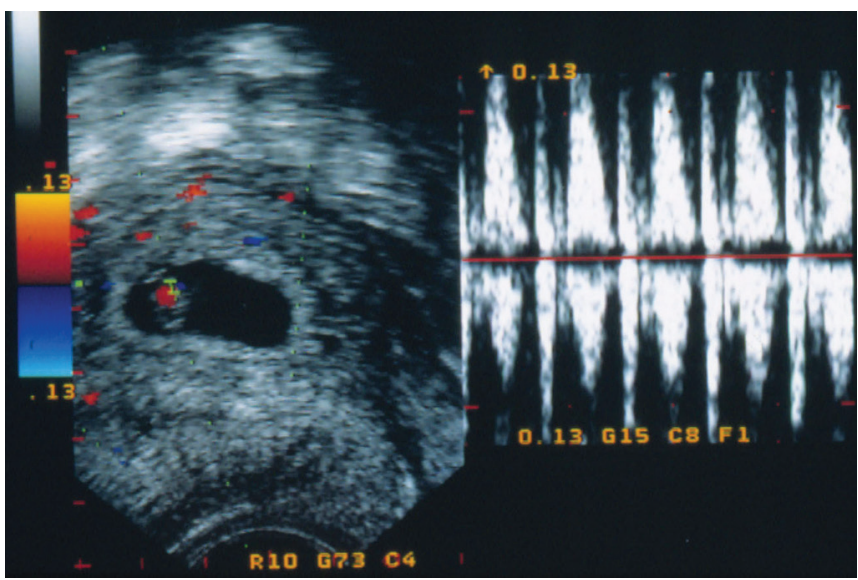

Fig. 5: The heart motion can be detected in most of the cases starting from a CRL of 3-4 mm

the definitive diagnosis for the viability of the pregnancy will be obtained.

More than $80 \%$ of the sonographic explorations performed in the 1st trimester of pregnancy, in asymptomatic women without risk factors, will be strictly normal. Anyway, as more precociously the first sonographic 
Ultrasonographic Signs of Poor Pregnancy Outcome

exploration is performed, higher will be the probability that we find abnormal data or not rigorous diagnoses, and with more probability a repetition of the sonographic exploration should confirm the normality. A pregnancy of 2 weeks less, in the 10th week, will allow to see a normal sac and an alive embryo of $16 \mathrm{~mm}$ of CRL, but if the sonographic exploration is performed in the 7th week, a small gestational sac of 8 or $10 \mathrm{~mm}$ of diameter will probably be the only finding. The confirmation that a pregnancy evolves correctly and with a prediction of good outcome (low abortion probability) is only obtained when a live embryo is visualized and history of associated risk factors don't exist. On the contrary, the confirmation that a pregnancy has been interrupted can only be made when an embryo is visualized with a certain size without heartbeat. When there is no embryo, except in cases when the gestational sac has reached a bigger size, another sonographic exploration 7 to 10 days later is to be performed.

\section{SONOGRAPHIC FINDINGS TO DIAGNOSE AN INTERRUPTED PREGNANCY}

The two types of spontaneous interruptions of pregnancy in patients without bleeding are, from a practical point of view, the differed or missed abortions, and the blighted ovum or anembryonic pregnancies (Table 2). Academically, the differed abortions were considered as those in which the measured CRL corresponded to 6 weeks less than the expected in an embryo lacking heartbeat (Fig. 6). Nowadays, due to better accessibility of women to the initial sonographic exploration, it is infrequent to reach a later stage without diagnosis, so this type of abortions, when the interruption is recent and bleeding has not begun, are called missed abortions. With regard to the anembryonic pregnancies, their frequency is much lower than what is thought from a clinical point of

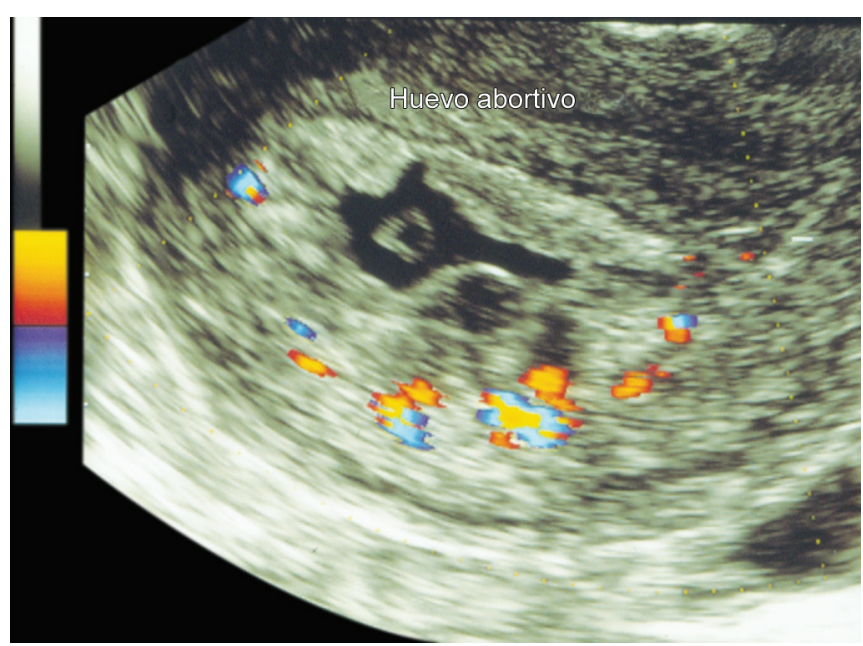

Fig. 6: Differed abortions were considered as those in which the measured CRL corresponded to 6 weeks less than the expected in an embryo lacking heart beat. The gestational sac is folding
Table 2: Summary of signs corresponding to interrupted pregnancy

\begin{tabular}{|c|c|}
\hline $\begin{array}{l}\text { Embryonic death } \\
\text { (differed or } \\
\text { missed abortion) }\end{array}$ & $\begin{array}{l}\text { Absence of heartbeat in embryo of } 5 \mathrm{~mm} \\
\mathrm{CRL} \text { as minimum (even in first sonographic } \\
\text { exploration) }\end{array}$ \\
\hline \multirow{3}{*}{$\begin{array}{l}\text { Blighted ovum } \\
\text { or anembryonic } \\
\text { pregnancy }\end{array}$} & $\begin{array}{l}\text { Gestational sac of } 25 \mathrm{~mm} \text { or more without } \\
\text { embryo (even in first sonographic exploration) }\end{array}$ \\
\hline & $\begin{array}{l}\text { For some authors, gestational sac of } 20 \mathrm{~mm} \\
\text { or more without yolk sac }\end{array}$ \\
\hline & $\begin{array}{l}\text { Gestational sac of } 16 \mathrm{~mm} \text { or more with yolk } \\
\text { sac and amniotic vesicle without embryo } \\
\text { ("empty amnion") }\end{array}$ \\
\hline $\begin{array}{l}\text { Interrupted } \\
\text { pregnancy }\end{array}$ & $\begin{array}{l}\text { Successive sonographic explorations: } \\
\text { Absence of significant changes in two } \\
\text { separate sonographic explorations } \\
7-10 \text { days when in the first sonographic } \\
\text { exploration a gestational sac of } 15-20 \mathrm{~mm} \\
\text { as minimum has been visualized }\end{array}$ \\
\hline
\end{tabular}

view. Anembryonic pregnancies are pregnancies initially with no embryo, that was dead precociously and was reabsorbed, and so is not sonographically visualized. All gestational sac in which an amniotic or a yolk sac is observed, although embryo is not seen, don't correspond to anembryonic pregnancies, since these structures require the development of an embryo to appear (Fig. 7).

The false-positive diagnoses are the really important mistakes. Based on early studies, a CRL of $5 \mathrm{~mm}$ without cardiac activity or an empty gestational sac measuring $16 \mathrm{~mm}$ in mean gestational sac diameter has been used as diagnostic criteria to confirm early pregnancy loss. Recently, several studies have been used to challenge these cutoffs. ${ }^{14}$ It has been demonstrated that a CRL cutoff of $5 \mathrm{~mm}$ was associated with an $8.3 \%$ false-positive rate for early pregnancy loss. A CRL cutoff of $5.3 \mathrm{~mm}$ was required to achieve a false-positive rate of $0 \% .{ }^{15}$ Similarly, there is a $4.4 \%$ false-positive rate for early pregnancy loss when using a mean gestational sac diameter cutoff of

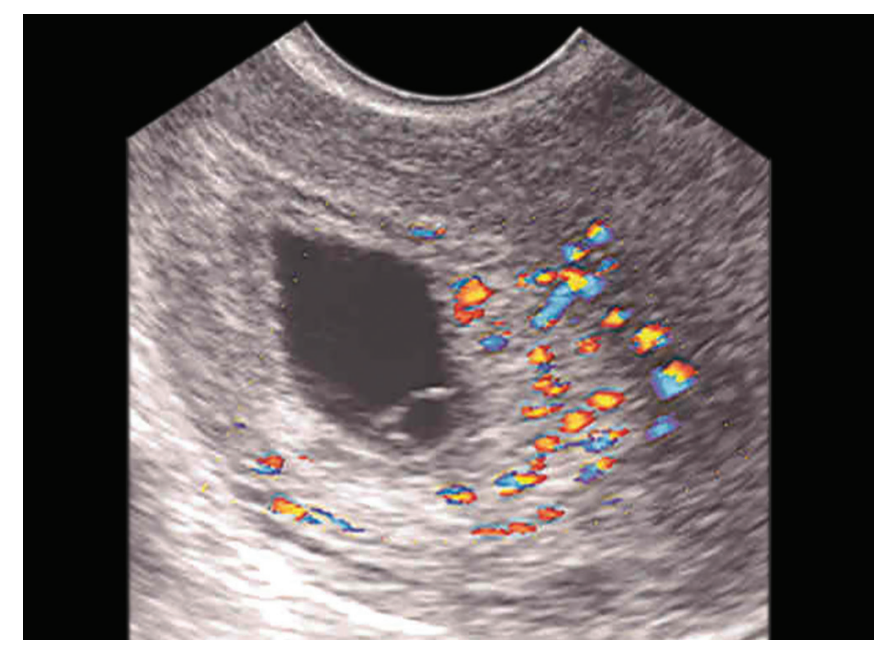

Fig. 7: A gestational sac in which a yolk sac is seen although embryo is not observed corresponding to a missed abortion 
$16 \mathrm{~mm}$. A mean gestational sac diameter cutoff of $21 \mathrm{~mm}$ (without an embryo and with or without a yolk sac) on the first ultrasound examination was required to achieve $100 \%$ specificity for early pregnancy loss. ${ }^{15}$

On the contrary, growth rates for gestational sac (mean gestational sac diameter) and the embryo (CRL) could not predict viability accurately. ${ }^{16}$ However, if a gestational sac was empty on an initial scan, the absence of a visible yolk sac or embryo on a second scan performed 7 days or later after the first scan could be diagnosed as pregnancy loss with a specificity near to $100 \%{ }^{16}$

Although a wide range of cutoff points have been proposed, they all include a certain margin of safety, the main cause of misdiagnosis is operator error, and this can occur irrespective of a chosen cutoff value. ${ }^{17}$

Thus, there are two types of false-positive diagnosis. The first is when the sonographist is not able to detect the heartbeat in an embryo that actually has heart motion, and would be motivated by a small size of the embryo, inadequate or obsolete team, or suboptimal visualization due to patient characteristics. The other type of error would be to consider that before a certain size of gestational sac, an embryo must be seen. The error is motivated by the selection of a low level from which we already diagnose anembryonic pregnancy, and that this level could correspond to the highest range in the normality. In the first case, it would suppose that after 1 week, for instance, in an embryo of 4 to $5 \mathrm{~mm}$ in the one that had not seen heartbeat, it will measure 9 to $10 \mathrm{~mm}$. In the second case, in a $21 \mathrm{~mm}$ diameter vesicle, in which the embryo was not seen, after 1 week, a 5 to $6 \mathrm{~mm}$ CRL and positive heartbeat embryo will be observed.

The London National Institute for Health and Care Excellence recommends that, in all cases, the diagnosis of pregnancy loss should be confirmed at a follow-up visit 7 to 14 days later or by a second observer to minimize the risk of diagnostic errors. ${ }^{18}$

We will describe now some of the cutoff values that have been used in different studies to diagnose a pregnancy loss:

- According to Preisler et al, ${ }^{19}$ the following indicated a miscarriage at initial scan: Mean gestational sac diameter $\geq 25 \mathrm{~mm}$ with an empty sac (specificity: $100 \%$ ) embryo with a CRL $\geq 7 \mathrm{~mm}$ without visible embryo heart activity (specificity: 100\%), mean gestational sac diameter $\geq 18 \mathrm{~mm}$ for gestational sacs without an embryo presenting after 70 days' gestation (specificity: $100 \%$ ), embryo with CRL $\geq 3 \mathrm{~mm}$ without visible heart activity presenting after 70 days' gestation (specificity: $100 \%)$. The following were indicative of miscarriage at a repeat scan: Initial scan and repeat scan after 7 days or more showing an embryo without visible heart activity (specificity: 100\%), pregnancies without an embryo and mean gestational sac diameter $<12 \mathrm{~mm}$ where the mean diameter has not doubled after 14 days or more (specificity: 100\%), pregnancies without an embryo and mean gestational sac diameter $\geq 12 \mathrm{~mm}$ showing no embryo heartbeat after 7 days or more (specificity: 100\%).

- The National Institute for Health and Care Excellence guidelines suggest that fetal demise should be suspected in the absence of heartbeat when CRL is greater than $7 \mathrm{~mm}$ or gestational sac measures more than $25 \mathrm{~mm}$ without a visible embryo. ${ }^{18}$

- According to Daya et $\mathrm{al}^{20}$ an embryo is not seen until the gestational sac measures $8.3 \mathrm{~mm}$ diameter, coincident with the 41st day of amenorrhea. However, it is always to be observed when the gestational sac reaches $14 \mathrm{~mm}$ diameter, in the 46th day of amenorrhea ( 6 weeks and 4 days).

- Goldstein et $\mathrm{al}^{21}$ inform that when the pregnancy is correctly developing, the gestational sac is reliably observed in the 5th week. When the sac measures $20 \mathrm{~mm}$ diameter, the embryo is observed in $100 \%$ of the cases. After 6 weeks and 4 days (46th day of amenorrhea), heartbeat is observed in $100 \%$ of the cases, and when the diameter is $30 \mathrm{~mm}$, in $100 \%$ of the normal cases, embryonic movements are also already present (8 weeks).

- Cho et $\mathrm{al}^{22}$ declare that some of the criteria in detecting spontaneous pregnancy losses are $8 \mathrm{~mm}$ diameter of the gestational sac without a visible yolk sac and also a gestational sac of 16 to $20 \mathrm{~mm}$ without embryonic heartbeats.

- Hernadi et $\mathrm{al}^{23}$ detected heartbeat in all the live embryos reaching $7 \mathrm{~mm}$ CRL. This author diagnosed blighted ovum or anembryonic pregnancy when the gestational sac was $20 \mathrm{~mm}$ diameter and lacked internal echoes. To confirm the diagnosis of "embryonic death" at the first sonographic exploration, the CRL should be higher than $10 \mathrm{~mm}$.

- Levi et $\mathrm{al}^{8}$ consider "not viable" all gestational sacs of more than $8 \mathrm{~mm}$ of diameter without yolk sac and of $16 \mathrm{~mm}$ or more without embryo. They diagnose embryonic death when the embryo is between 4 and $5 \mathrm{~mm}$ CRL. Several cases with CRL smaller than $4 \mathrm{~mm}$ in those that heartbeat was not detected evolved correctly in their series.

- Brown et $\mathrm{al}^{24}$ recommend waiting until $5 \mathrm{~mm}$ CRL to confirm embryonic demise if heartbeat is not detected.

- Bernard and Cooperberg, ${ }^{25}$ in the differentiation among blighted ovum and "viable precocious pregnancy," consider that although the visualization of sacs with $20 \mathrm{~mm}$ or more without embryo is a sign of poor prognosis, definitive signs don't exist, so recommend to repeat the sonographic exploration after 1 to 2 weeks. 
- Nyberg et $\mathrm{al}^{26}$ recommend to wait to observe a gestational sac of more than $20 \mathrm{~mm}$ of diameter without yolk sac or a sac of $25 \mathrm{~mm}$ diameter with distorted aspect without embryo to consider a pregnancy as not viable.

- Perriera and Reeves ${ }^{27}$ recommend to wait until the gestational sac measures $20 \mathrm{~mm}$ without an embryonic pole to diagnose an interrupted gestation because there were found several pregnancies with a gestational sac of $18 \mathrm{~mm}$ that later were found to have a living embryo.

- McKenna et $\mathrm{al}^{28}$ report that between the 6th and the 10th week, the amniotic cavity is similar to the size of the embryo, and the visualization of an amniotic cavity without embryo corresponded to an "empty amnion" and diagnose interrupted pregnancy. This author communicates that before gestational sac reaches $16 \mathrm{~mm}$ or more, when the yolk sac is identified and neither embryo nor heartbeat is detected, and an empty amniotic sac is seen, an interrupted pregnancy can be diagnosed.

For a definite diagnosis of embryonic death, it is necessary to wait to see an embryo with a minimum CRL of 5 to $6 \mathrm{~mm}$ lacking heartbeat. For the diagnosis of blighted ovum or anembryonic pregnancy in a first sonographic exploration, it seems reasonable to wait for a $25 \mathrm{~mm}$ gestational sac, equivalent to 7 weeks pregnancy with conception on the 14th day of the cycle. This corresponds to a pregnancy in which in 100\% of the cases an alive embryo would be visualized if it correctly develops. In all other cases, the sonographic exploration must be repeated after 7 to 10 days. In the great majority of the cases, the second sonography will allow us to confirm the diagnosis of normal or interrupted pregnancy.

\section{POOR PROGNOSIS OF PREGNANCY, SONOGRAPHIC FINDINGS}

There exist some circumstances that, when present in a sonographic exploration performed in the 1st trimester of the pregnancy, hampers the prognosis; although they don't allow the definitive diagnosis of "interruption of the development," they determine that the prognosis for normal outcome is reduced (Tables 3 and 4). Stamatopoulos et $\mathrm{al}^{29}$ studied more than 30 historical, clinical, and ultrasonographic variables to create a prediction model for miscarriage and found that the most significant independent prognostic variables were maternal age, embryonic heart rate, logarithm [gestational sac volume/ CRL], CRL, and the presence or absence of clots per vagina at presentation.

In the days leading to the detection of the development, some phenomena are usually detected. However,
Table 3: Summary of signs of poor prognosis for fetal viability

Anomalies of the Precocious oligoamnion: When the
gestational sac difference between the average diameter of the gestational sac and the CRL is smaller than $5 \mathrm{~mm}$, poor prognosis

Very thin decidual reaction $(\mathrm{mm})$ for the corresponding gestational age (weeks) (>3 difference)

Low implantation

Distorted aspect

Alterations of the Bradycardia is always a sign of poor heart frequency prognosis. It should be interpreted as a function of the gestational age Frequencies under $85 \mathrm{bpm}$ until the 7 th week and under $100 \mathrm{bpm}$ from this moment on, poor diagnosis

Small live embryo Especially in women with regular cycles, for the LMP the visualization of a CRL smaller in at least 1 week to that corresponding for the LMP increases the risk for abortion

Anomalies of the Alterations in the size (big vesicles, more yolk sac than $6 \mathrm{~mm}$ of diameter) increase the risk Alterations in the structure (hyperechogenic vesicle) have poor prognosis

Reverse Risk for abortion increased

implantation Intrauterine bleeding (hematomas)

Big hematomas, mainly retrochorionic, maximum risk. Subchorionic hematomas located in corpus or fundus more risk next to the uterine cervix

If no vaginal bleeding or small size of hematoma, low risk

Fetal movements Absence of fetal movements, starting from the 8th week

Doppler Poor color map around the gestational sac Values of Doppler flow in uterine, radial, arcuate, spiral, retrochorial, and intervillous arteries, as well as the umbilical artery in the first trimester of pregnancy have limited clinical applicability

Other factors Existence of associated pathology:

Myomas, malformations

Uterine hemorrhage

Maternal age over 35 years

Antecedent of one or more abortions (as more abortions, more risk)

Serial hormonal determinations. Two

$\beta$-hCG determinations separate $2-3$ days First-trimester chorionic bumps

none of them is sufficiently reliable as to emit definitive diagnoses.

\section{Anomalies of the Gestational Sac}

The gestational sac and the CRL develop simultaneously. It is possible to check how between the 6th and the 10th week, the difference usually reaches 15 to $20 \mathrm{~mm}$. Bromley et $\mathrm{al}^{30}$ communicate that when the difference between the diameter of the gestational sac and CRL is less than $5 \mathrm{~mm}$ (precocious oligoamnion), abortion occurred in $95 \%$ of the 
Table 4: Society of radiologists in ultrasound guidelines for transvaginal ultrasonographic diagnosis of early pregnancy loss ${ }^{74}$

\begin{tabular}{ll}
\hline $\begin{array}{l}\text { Findings diagnostic of early } \\
\text { pregnancy loss* }\end{array}$ & $\begin{array}{l}\text { Findings suggestive, but not } \\
\text { diagnostic, of early pregnancy } \\
\text { loss* }\end{array}$ \\
$\begin{array}{l}\text { CRL of } 7 \mathrm{~mm} \text { or greater and } \\
\text { not heartbeat }\end{array}$ & $\begin{array}{l}\text { CRL of less than } 7 \mathrm{~mm} \text { and no } \\
\text { heartbeat }\end{array}$ \\
$\begin{array}{l}\text { Mean sac diameter of } 25 \mathrm{~mm} \\
\text { or greater and no embryo }\end{array}$ & $\begin{array}{l}\text { Mean sac diameter of } 16-24 \mathrm{~mm} \\
\text { and no embryo }\end{array}$ \\
$\begin{array}{l}\text { Absence of embryo with } \\
\text { heartbeat } 2 \text { weeks or more }\end{array}$ & $\begin{array}{l}\text { Absence of embryo with heartbeat } \\
7-13 \text { days after an ultrasound }\end{array}$ \\
after a scan that showed a & scan that showed a gestational \\
gestational sac without a & sac without a yolk sac
\end{tabular}
yolk sac

Absence of embryo with heartbeat 11 days or more after a scan that showed a gestational sac with a yolk sac

Absence of embryo with heartbeat 7-10 days after an ultrasound scan that showed a gestational sac with a yolk sac Absence of embryo for 6 weeks or longer after LMP Empty amnion (amnion seen adjacent to yolk sac, with no visible embryo)

Enlarged yolk sac (greater than $7 \mathrm{~mm}$ )

Small gestational sac in relation to the size of the embryo (less than $5 \mathrm{~mm}$ difference between mean sac diameter and $\mathrm{CRL}$ )

*These are the radiologic criteria only and do not replace clinical judgment; ** when there are findings suspicious for early pregnancy loss, follow-up ultrasonography at 7-10 days to assess the pregnancy for viability is generally appropriate

cases (Fig. 8). Dickey et a ${ }^{31}$ report that when the difference among these two measures was less than $5 \mathrm{~mm}$, abortion occurred in $80 \%$ of the cases; when the difference was between 5 and $7.9 \mathrm{~mm}$, abortion occurred in $26.5 \%$ of the cases, and when the difference was over $8 \mathrm{~mm}$, abortion occurred in only $10.6 \%$ of the cases. ${ }^{32}$

\section{Anomalies of the Heart Frequency Interpreted as a Function of the Gestational Age (GE) or CRL}

\section{Bradycardia or Relative Bradycardia}

The ascent of the fetal heart rate (FHR) is characteristic until the 10th week, from $90 \mathrm{bpm}$ in the first weeks of visualization up to 180 to $190 \mathrm{bpm}$ in the 12th week. From this moment, FHR diminishes progressively until reaching the 140 to $150 \mathrm{bpm}$ in the 20th week. However, important variations exist in the frequency in every week of pregnancy among the different authors. Merchiers et $a l^{33}$ give importance to a decrease of the heart frequency taking place in successive sonographic explorations between the two. For Laboda et $\mathrm{al}^{34}$ an FHR under $85 \mathrm{bpm}$ comports very poor prognosis, since in its series, all the embryos that presented this finding ended in miscarrying. May and Sturtevant $t^{35}$ also find poor prognosis in this finding: 6 out of 11 cases with FHR less than $85 \mathrm{bpm}$ between the 4.5th and the 7.3rd week miscarried.

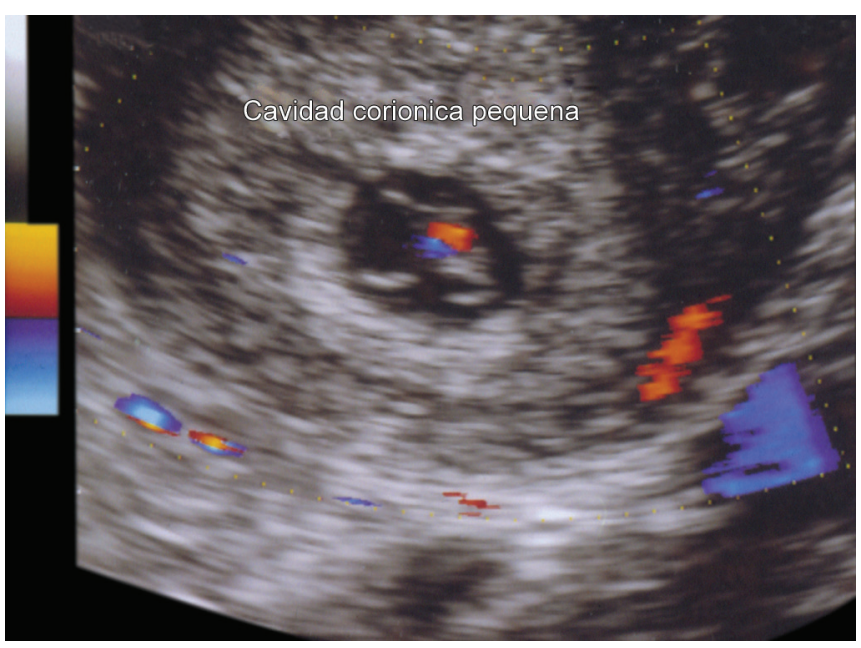

Fig. 8: Gestational sac showing precocious oligoamnion. This is a good predictor for abortion

Benson and Doubilet ${ }^{36}$ set the limit as $90 \mathrm{bpm}$ for the whole 1st trimester to affirm that a poor prognosis exists. In their series, all the cases which had an FHR under $70 \mathrm{bpm}$ ended in abortion. Between 70 and $79 \mathrm{bpm}$, there were $91 \%$ of abortions, and between 80 and $89 \mathrm{bpm}, 70 \%$ of abortions. Doubilet and Benson ${ }^{37}$ suggest that an FHR more than $100 \mathrm{bpm}$ until the $6.2 \mathrm{nd}$ week and superior to $120 \mathrm{bpm}$ between the 6.3rd and the 7th week are signs of good prognosis. When they observe an inferior FHR of $110 \mathrm{bpm}$ during the 7th and 8th weeks, they consider it a sign of poor prognosis. Stefos et $\mathrm{al}^{38}$ present in their series that, when an FHR less than $85 \mathrm{bpm}$ exists between the 6th and 8th week, any fetus will survive. For this author, when between the 6th and the 7th week the FHR is between 116 and $125 \mathrm{bpm}$, the prognosis is good, as is when the FHR is more than $146 \mathrm{bpm}$ between the 8 th and the 9th week. Anyway, any finding except the absence of heartbeat is able to diagnose embryonic death definitively. However, the scientific evidence allows it to be possible to give more and more precise diagnosis. In general, heart frequencies under 80 to $90 \mathrm{bpm}$ until the 7th week and under $100 \mathrm{bpm}$ from this moment on are associated with an adverse result, and high abortion probability.

\section{Anomalies of the Yolk Sac (Size, Shape, Ecogenicity)}

The yolk sac is the first extraembryonic structure that appears and is visible practically in all the pregnancies between the 5 th and the 12 th week. ${ }^{39}$ The yolk sac can be observed initially when the diameter of the gestational sac reaches $3.7 \mathrm{~mm}$, in the 36th day from the LMP, and is reliably observed when the diameter is from $6.7 \mathrm{~mm}$, in the 40th day of amenorrhea. Furthermore, for Levi et $\mathrm{al}^{8}$ the yolk sac should always be observed when the diameter of the gestational sac is more than $8 \mathrm{~mm}$ (corresponding to 33 days), so its absence would suppose for him an approach bigger than loss of gestation. 


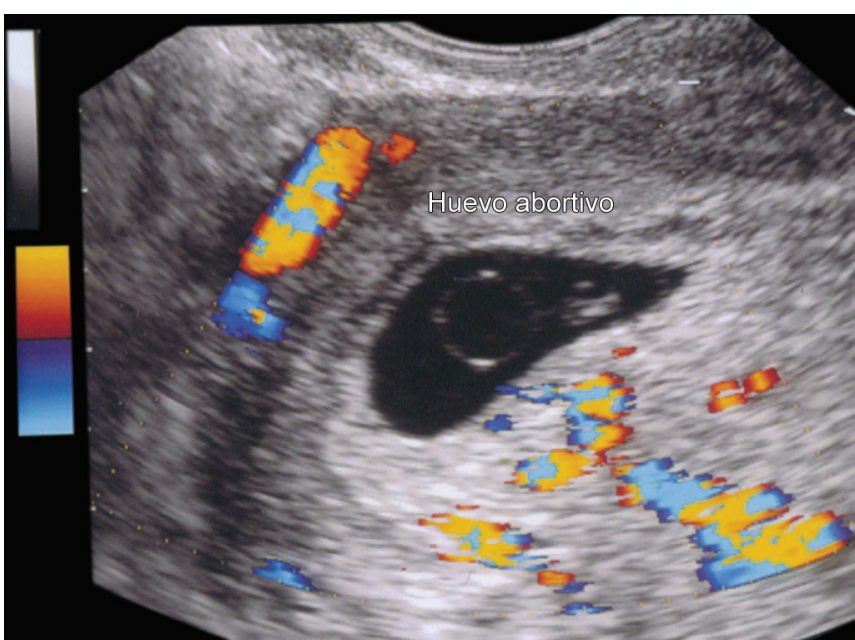

Fig. 9: Yolk sac of $8 \mathrm{~mm}$ (more than 2 standard deviations)

The main interest of the visibility of the yolk sac has for the ecographists resides in, i.e., the first identifiable structure in the gestational sac, preceding 4 to 7 days to the visualization of the embryo. Their aspect is an echogenic circle that defines a sonolucent area inside the chorionic cavity, extraamniotically located.

Some anomalies are described in their initial development as shape and volume alterations. ${ }^{40,41}$

In general, it is difficult to make important clinical decisions (as in diagnosing a pregnancy interruption) based on findings related to the yolk sac. This is a structure with important variations related to their size and dimensions. The visualization is not also absolutely safe, even in pregnancies of normal course. The alterations at their level are usually late, and it is believed that they are consequences of the process that determines the abortion, not the cause. However, multiple publications have been in charge of their measure, of the valuation of their characteristics, and of the epidemic analysis of their association with a poor outcome of the pregnancy.

Lindsay et $\mathrm{al}^{42}$ refer that the existence of a yolk sac of more than two standard deviations (SDs) above those expected for the gestational age supposes a poor prognosis. Any case evolved favorably with a yolk sac bigger than $5.6 \mathrm{~mm}$ under the 10th week in their series (Figs 9 to 11). This agrees with the data from Kupesic and Kurjak, ${ }^{43}$ who inform of a poor prognosis in yolk sacs with abnormal size and abnormal Doppler vascularization. Iniesta et $\mathrm{al}^{44}$ inform that the alterations in the yolk sac as for their size, the shape, or the echogenicity are parameters that guide the normal or pathological development of the pregnancy. Of the 100 patients in their series, 87 (87\%) had a normal development and evolved correctly until the end of the first trimester (control group); 13 (13\%) had an abnormal course of the pregnancy (study group). Of the 87 patients with correct development, 3 had a diameter of yolk sac of more than 1 SD. Of the 13

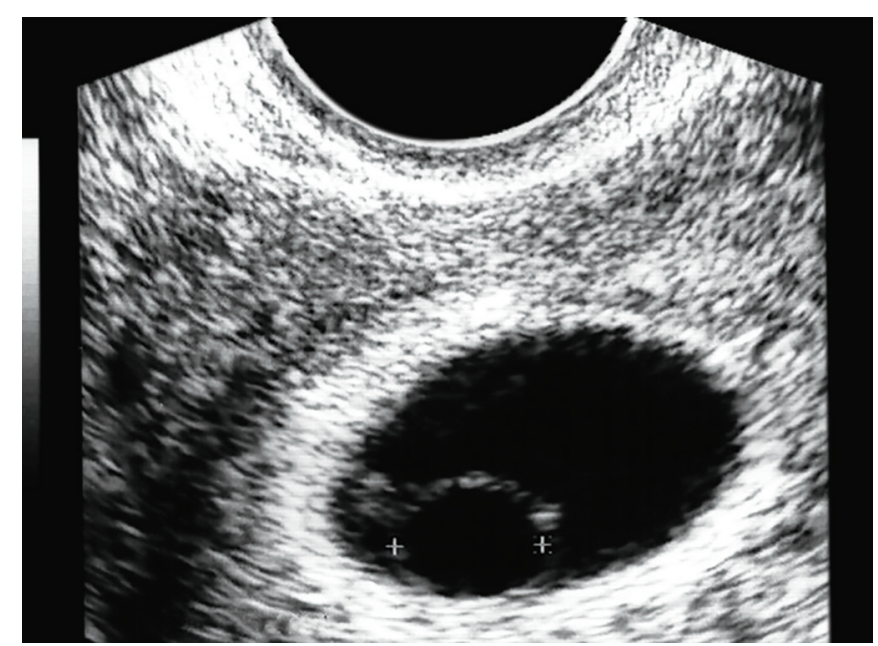

Fig. 10: Giant yolk sac. This sign is rapidly and easily appreciated in the sonographic exploration

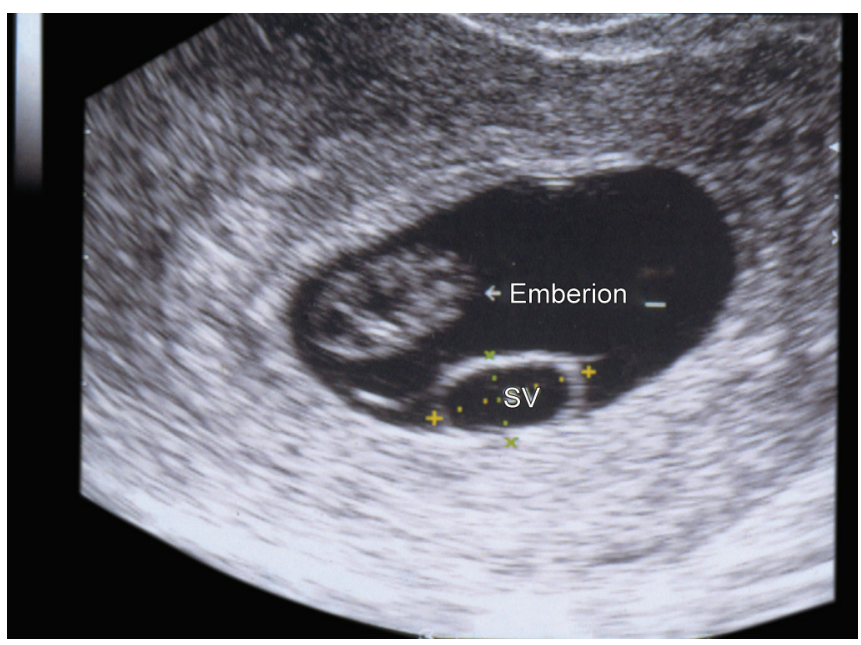

Fig. 11: Yolk sac of $9 \mathrm{~mm}$. This is very sensitive marker for abortion

patients with abnormal course, 6 had a diameter of yolk sac bigger than 1 SD. They conclude that the sensitivity of the size of the yolk sac to predict an abnormal course of the pregnancy is $92.3 \%$, the specificity $66.6 \%$, the positive predictive value (PPV) 96.5\%, and the negative predictive value (NPV) 46\%; and when some of these anomalies appear, it is necessary to closely follow the pregnancy. In this line, Cho et $\mathrm{al}^{22}$ studied 154 women form their 6th until their 10th week of gestation, concluding that none of them with normal pregnancies had a deformed or absent yolk sac. Also, it has been mentioned that if the yolk sac reaches $3.3 \mathrm{~mm}$, there has to be an embryo with positive heartbeats; if it is not seen and the yolk sac is $4.2 \mathrm{~mm}$, at least it can lead to the diagnosis of miscarriage.

The regressive yolk sac is sonographically observed by a progressive increase of the refrigency until the more extreme form that would be the calcification of the sac (Fig. 12).

Filly et $\mathrm{al}^{45}$ suggest that another sign of the high risk of abortion is the "yolk stalk sign," which is described as a separation of an embryo with a CRL of $5 \mathrm{~mm}$ or less from the yolk sac. They suggest that it will indicate 


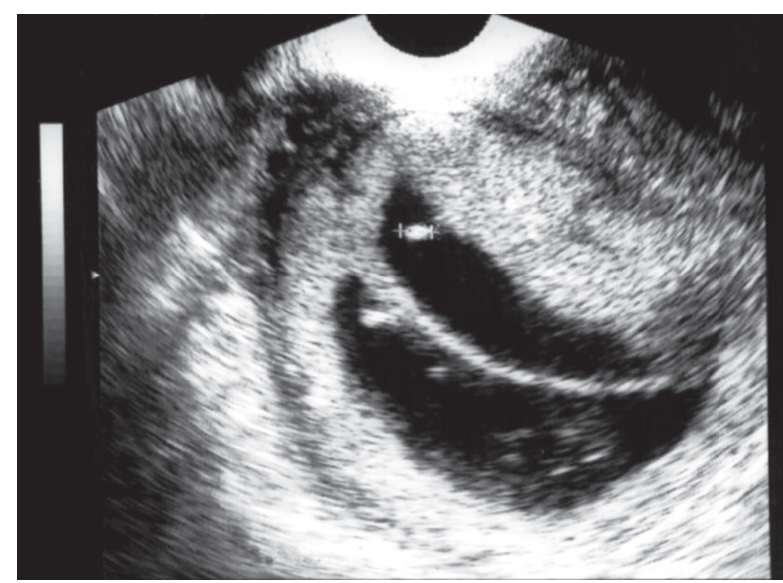

Fig. 12: The regressive yolk sac is observed by a progressive increase of the internal refrigency as seen in both yolk sacs of this multiple pregnancy

the development of the yolk stalk, which only develops at a more advanced stage of gestation that would have been deduced from the CRL alone, so it may indicate a pregnancy that has stopped its growth.

\section{Trophoblastic Thickness at the Embryonic Implantation Site}

Bajo et $\mathrm{al}^{46}$ describe the trophoblastic thickness at the embryonic implantation site in a prospective, observational study in 592 normal pregnancies in whom serial ultrasound scans were performed from 5 th to 12 th weeks of pregnancy. Trophoblastic thickness was measured at the embryonic implantation site to determine the significance of the difference between the gestational age in weeks and the trophoblastic thickness in millimeters. A difference of more than 3 was highly predictive of poor pregnancy outcome (Fig. 13). The sensitivity of this sign in the prediction of spontaneous abortion was $82 \%$, the specificity was $93 \%$, the positive predictive value was $63 \%$, and the negative predictive value was $97 \%$.

\section{Intrauterine Bleeding, Hematoma}

The existence of liquid collections, mainly in subchorionic situation, is a relatively frequent finding in sonographic explorations performed during the 1st trimester of the pregnancy (Fig. 14). Some of these images are evident, they have a great size and they coincide with clinical symptomatology (vaginal bleeding), while others are casual findings in asymptomatic women and have a minimum volume. Discrepancies exist as for the risk and their association with abortion as a function of the approaches used for the diagnosis of intrauterine hemorrhage. Dickey et $\mathrm{al}^{47}$ demonstrated with Doppler color that in $37 \%$ of the sonographic explorations in the 1 st trimester, subchorionic bleeding exists, and that in $47 \%$ of the cases, subchorionic liquid is detected. Thus,

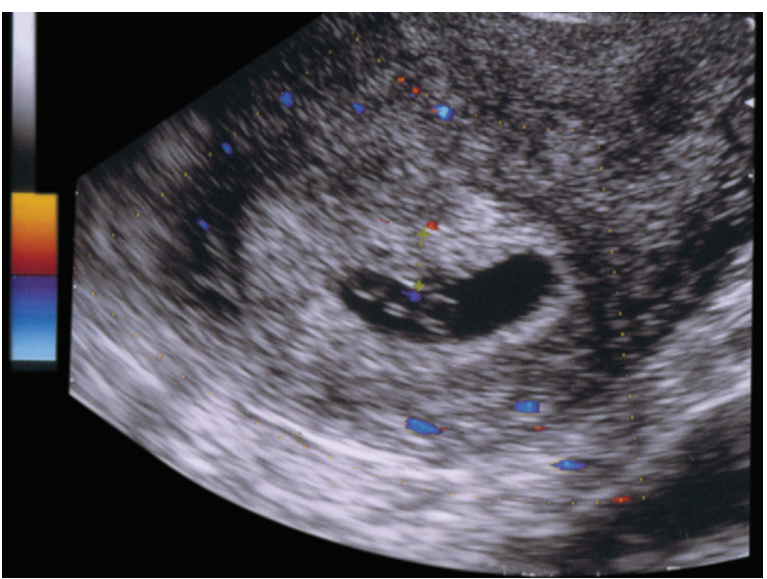

Fig. 13: A thin trophoblast is seen in this gestation. A difference of more than 3 between gestational age in weeks and the trophoblastic thickness in millimetres is highly predictive for poor pregnancy outcome

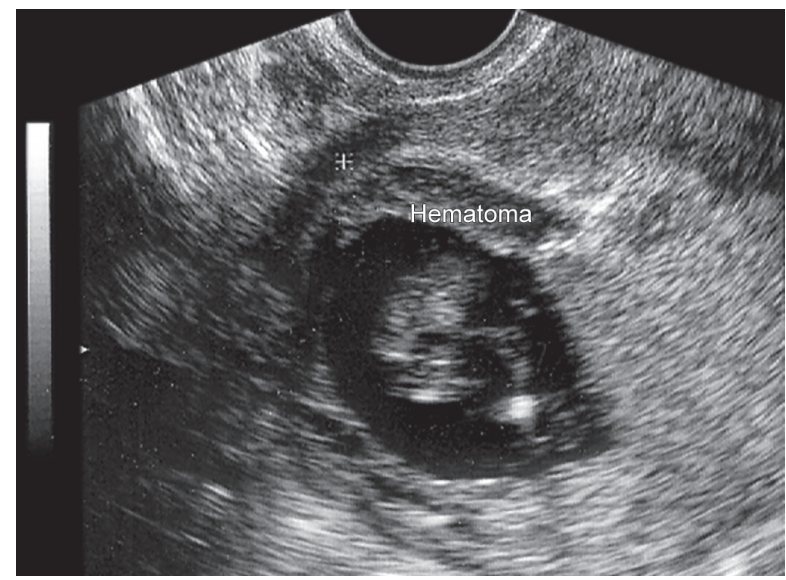

Fig. 14: The existence of liquid collections in subchorionic situation is a frequent finding in the explorations performed in the 1 st trimester

the liquid and the subchorionic bleeding are frequent discoveries in the early pregnancy and they are not associated with embryonic deaths unless accompanied by vaginal bleeding. Stabile et $\mathrm{al}^{48}$ state that the existence of small subchorionic hematomas (less than $16 \mathrm{~mL}$ ) in women with genital bleeding doesn't increase the risk for abortion in comparison to women with bleeding without hematoma.

With regard to the diagnosis that has the size and the localization of the hematoma, Glavind et $\mathrm{al}^{49}$ don't find a relationship between the size of the hematoma and the week of pregnancy in which it was diagnosed with the outcome of the pregnancy. For this author, the retrochorionic or subplacental localization has worse prognosis than the subchorionic localization (Fig. 15). For Kurjak et $\mathrm{al}_{1}^{50}$ the subchorionic hematomas influence the abortion frequency ( $17 \%$ in study group vs $6.5 \%$ in the control group). Neither influences the size of the hematoma a lot, being transcendent of the localization. The hematomas in uterine corpus or fundus have worse prognosis than those located near the uterine cervix (Fig. 16). Kurjak 


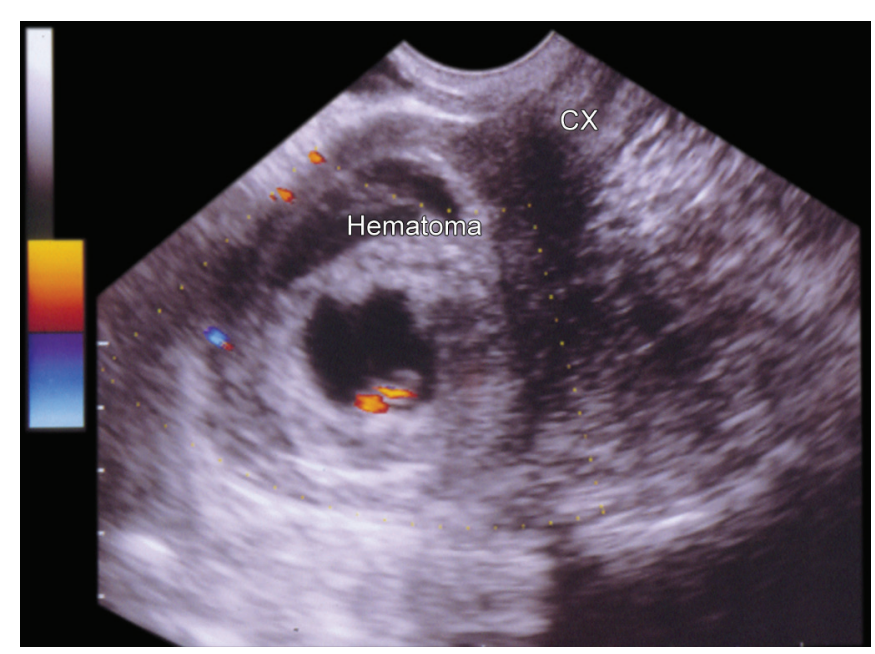

Fig. 15: The retrochorionic or subplacental localization have worse prognosis that the subchorionic localization

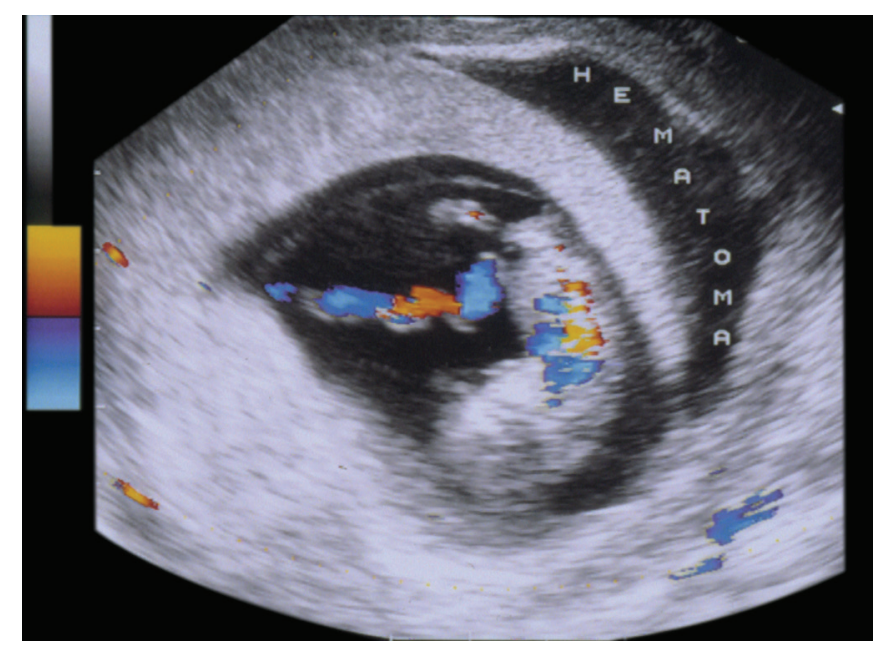

Fig. 16: Haematomas located in uterine corpus or fundus have worse prognosis than those located near the uterine cervix et $\mathrm{al}^{51}$ find a higher resistance index (RI) of the spiral arteries in cases with retrochorionic hematoma than in controls, due to the mechanism of compression of the hematoma.

For Ball et al, ${ }^{52}$ it is not clear that subchorionic bleeding is the cause or simply an underlying process, i.e., the one that produces the negative effects. They present an interesting study in which the patients are divided into three groups: The first is formed of women that present with subchorionic bleeding; the second is a control group of women without hematoma; the third is another control group without hematoma but with vaginal bleeding. When they perform comparisons with controls without having bled, an odds ratio (OR) of 2.8 is obtained for abortion, 4.5 for stillbirth, 11.2 for abruptio placentae, and 2.6 for preterm birth. When comparing with controls with bleeding, all the ORs increase except the corresponding one for abortion. The weight at birth is diminished when comparing it with the two control groups. The genital bleeding by itself is able to increase the abortion risk. Bennett et a ${ }^{53}$ compare the abortion frequency in women with genital bleeding and subchorionic hemorrhage. When the hematoma is big, the frequency of abortions is $18.8 \%$, if medium, $9.2 \%$, and $7.7 \%$ if small. With women older than 35 years, the abortion rate is $13.8 \%$; in comparison, it is $7.3 \%$ in women younger than 35 years. When the bleeding appeared before the 8th week, the frequency was $13.7 \%$, while if it appeared later than the 8 th week, the rate is reduced to $5.9 \%$.

The presence of scarce quantity of retrochorial liquid has less implications when it is observed as an isolated finding and in the context of a rigorously normal sonographic exploration in a pregnancy of normal course. The existence of a subchorionic hemorrhage, especially when associated with vaginal bleeding, increases the abortion risk and demands to perform other sonographic explorations a few days later. New sonographic explorations are justified when small or moderate hemorrhage exists. The worst prognosis are the big size hematomas (more than $40-50 \mathrm{~mL}$ ), especially if located next to the uterine neck, in uterine corpus or fundus. The retrochorionic or subplacental hematomas, especially if moderate or big, always carry a poor diagnosis. The frequency of visualization of these images is low, probably because a rapid chorial detachment develops leading to abortion, with bleeding and expulsion of remnants. Another uncommon type of hematoma or intrauterine bleeding is the preplacental one that appears after the realization of invasive techniques that need the introduction of a needle in the uterine cavity. In general, they are moderate and evolve favorably, although threatened miscarriage in the first trimester is associated with an increased incidence of adverse pregnancy outcome, independently of the presence of an intrauterine hematoma. ${ }^{54} \mathrm{Nagy}$ et $\mathrm{al}^{55}$ compared perinatal outcome in 187 pregnant women with intrauterine hematoma and 6,488 controls in whom hematomas were not detected at 1 st trimester. They conclude that the sonographic presence of an intrauterine hematoma during the 1 st trimester identifies a population of patients at increased risk for adverse pregnancy outcomes. ${ }^{55}$ In other occasions, they reach such a volume that cause an effect of occupation of the chorionic cavity, with effect of fetal death because of the compression (Fig. 17).

Poulose et $\mathrm{al}^{56}$ studied 370 pregnant women with vaginal bleeding. There were found statistically significant differences depending on the quantity of bleeding, the ones that bled like menstruation in quantity or more had more miscarriages, even though more than $75 \%$ of their patients continued to viability. They also studied the bleeding associated with hematoma, declaring that there is strong evidence to suggest that finding a hematoma can predict a higher rate of miscarriage (18 vs7.6\%). 


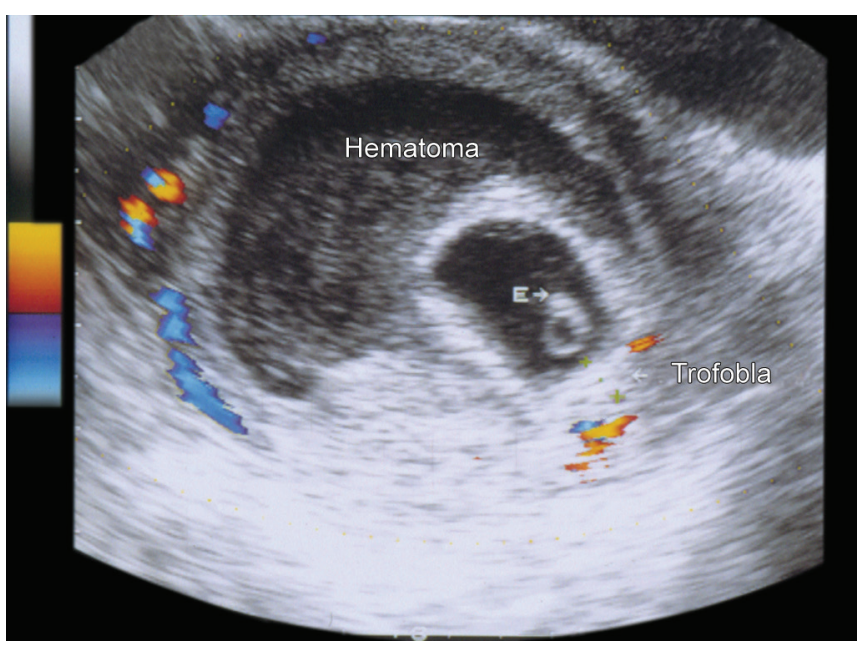

Fig. 17: Large haematoma causing some distortion effect in the gestational sac

\section{Small for Gestational Age CRL}

In general, when a small for gestational age CRL with positive heartbeat embryo is observed, a pregnancy of less time is the first diagnosis to approach. This is frequent in women with long or irregular cycles. However, sometimes it may be observed in normal cycle women. First of all, the date of conception should be corrected, but data that allow associating this alteration with a higher risk of poor pregnancy outcomes exist (Fig. 18).

Koornstra and Exalto ${ }^{57}$ inform that $22.7 \%$ of the embryos from regular cycle women have CRL inferior in 1 week or more than that expected from the LMP. Analyzing the results observed among these embryos, a rate of abortion of $16 \%$ exists, in comparison with only $5 \%$ in the embryos with correct LMP.

Leelapatana et al ${ }^{58}$ communicate that a small for gestational age CRL in comparison with the prospective one during the 1st trimester of pregnancy could be associated with triploidies, but not to the 18 and 21 trisomies. Later, Bessho et al ${ }^{59}$ communicated that fetuses finishing in miscarriage had a quotient measured CRL/expected CRL of 0.74 , in comparison with the 0.98 observed in fetuses that didn't miscarry. This author doesn't find differences in the quotient among chromosomically normal and abnormal fetuses. The information has also been confirmed in the series from Coulam et al ${ }^{60}$ who find no differences in the frequency of blighted ovum and small for gestational age CRL among chromosomically normal and abnormal fetuses.

\section{Pattern of Fetal Movements}

Along the sonographic chronology of findings in a normal pregnancy, the existence and verification of fetal movements should be contemplated.

In a classic publication by Anderson, ${ }^{61}$ the results obtained in a series of 149 cases presented with threatened

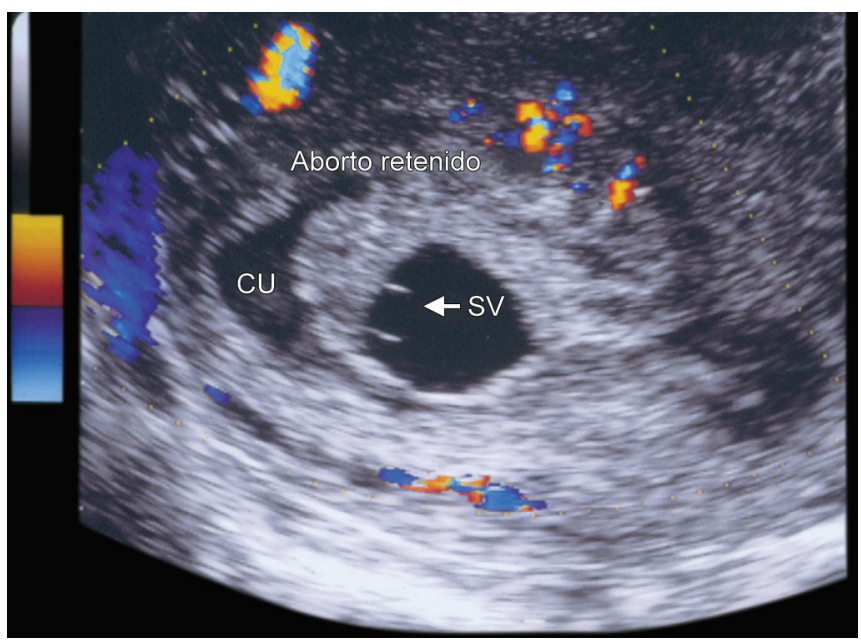

Fig. 18: Small CRL for the gestational age, as referred to gestational sac

abortion and more than 7 weeks of gestational age. Only 2 of 65 pregnancies that later aborted presented fetal movements. On the contrary, 64 of 72 normal pregnancies presented fetal movements. So the absence of fetal movements after a relatively long period of sonographic exploration, especially above the 8th week, should also be considered as a sign of poor prognosis.

\section{Doppler Flow Alterations}

The number of publications performed on purpose of the analysis of the Doppler velocimetry in the first stadiums of the normal and pathological pregnancies during the last years is abundant. The knowledge of the data that the investigators contribute has an enormous interest to improve our knowledge on the phenomena that exist in the placentation process and development of the embryo from their first. Kurjak and Kupesic ${ }^{62}$ refer that the process of trophoblastic invasion of the decidua is progressive, mediated by the action of proteolytic enzymes that facilitate the penetration and maternal erosion of the capillary arteries and the formation of lagoons. That is why variations of the flows that can be measured in the uterine, retrochorionic, and intervillous arteries exist, in the 1st trimester of pregnancy (Fig. 19). This is why the pulsatility index (PI) and high RI in the 1st trimester should not be interpreted as an unlikely result, like it would be made in the 2 nd trimester as Jaffe et $\mathrm{al}^{63}$ inform. This author explains ${ }^{64}$ how the intervillous circulation persists until the late 1st trimester. In complicated pregnancies, analyzed precociously, the uteroplacental circulation is different to that of normal pregnancies. In these abnormal pregnancies, the intervillous flow is increased. The hypothesis, i.e., based on other studies establishes that the embryo of a pregnancy of normal course favors an atmosphere with a low concentration of tissular oxygen in placental tissues. Mercé et $\mathrm{al}^{65}$ measured in 108 pregnancies between the 4 th and the 15 th week the velocity 


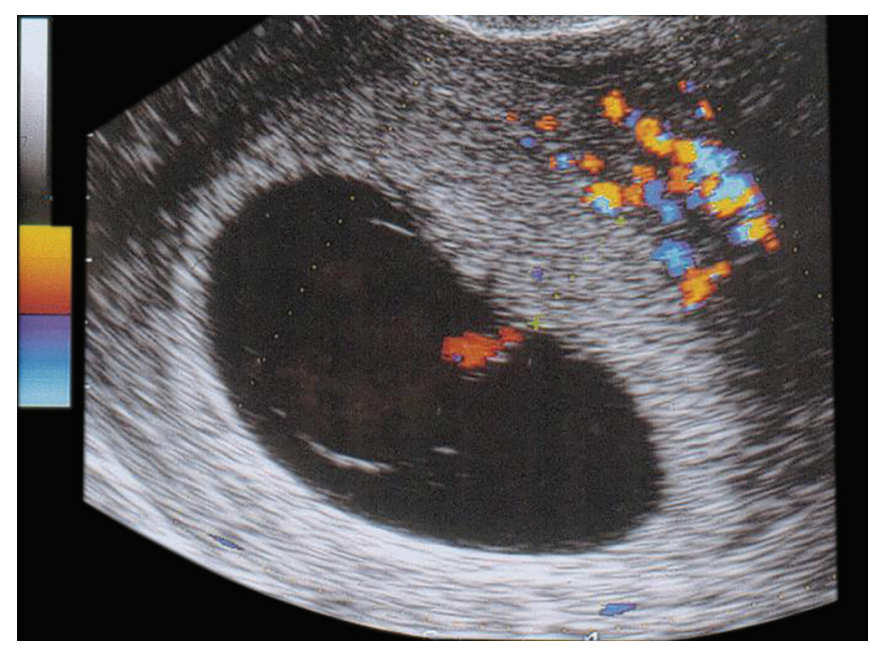

Fig. 19: Doppler flows that can be measured in the uterine retrochorionic and intervillous arteries in the first trimester of pregnancy

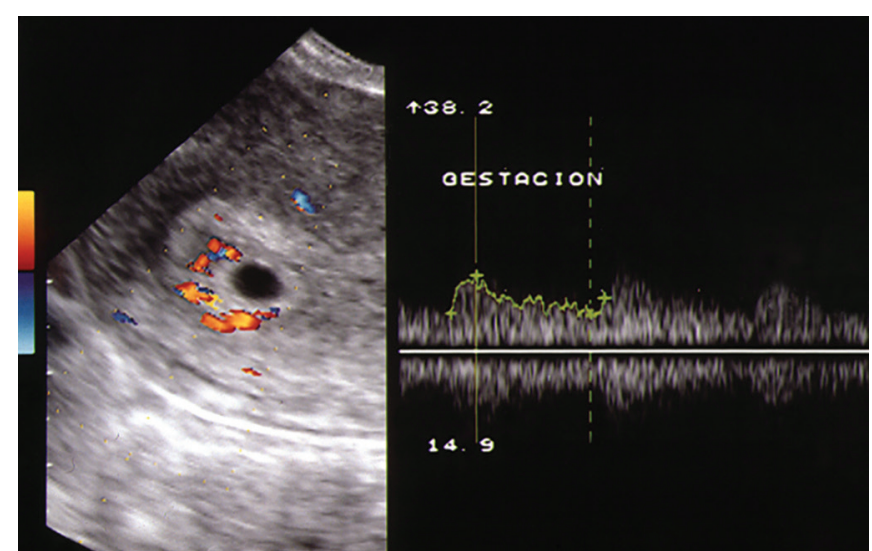

Fig. 21: The use of transvaginal colour Doppler is not helpful for predicting pregnancy outcome in cases of living embryo

of systolic peak, PI, and RI in retrochorionic arteries and fetal umbilical artery. The most precocious sign in retrochorionic circulation was obtained in the 4.5th week, and the most precocious of umbilical artery at the end of the 5 th week. Their results indicate that as gestational age increases, the systolic peak of the retrochorionic, intervillous, and umbilical arteries increase, while PI and RI diminish. Kurjak and Kupesic ${ }^{66}$ again assessed yolk sac morphology and vascularity and intervillous blood flow in normal early pregnancy and missed abortion in a prospective analysis of 87 normal pregnancies and 48 missed abortions between 6 and 12 weeks gestation. They conclude that progressive decrease of yolk sac vascularity coincides with visualization of more prominent colorcoded areas within the intervillous space. In patients with missed abortion, such changes do not occur.

In general, most of the authors do not find differences in the Doppler indexes among normal outcome pregnancies and those ending in abortion. Jauniaux et $\mathrm{al}^{67}$ compare 30 confirmed abortions with 30 normal

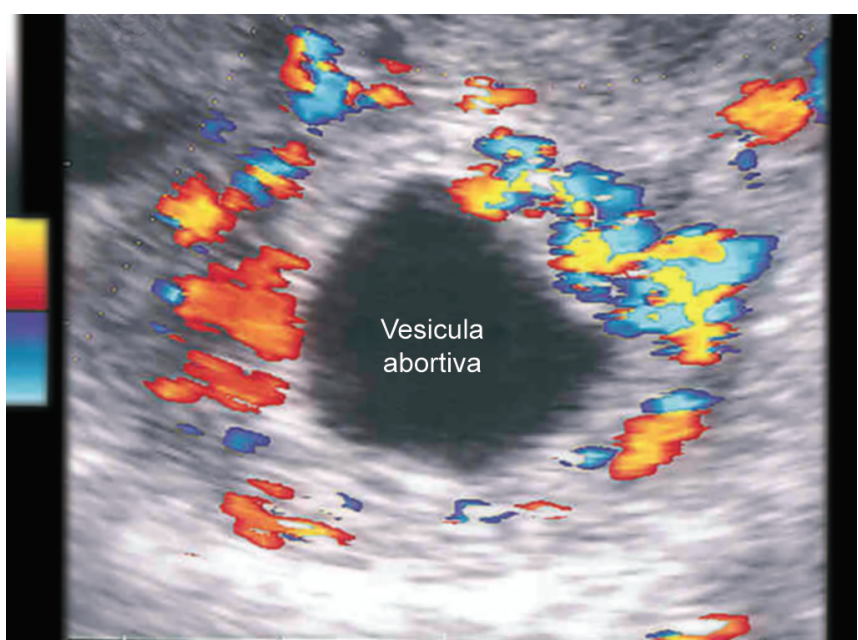

Fig. 20: The premature access of maternal blood to the intervillous space has broken the embryonic-maternal interface, probably the cause that determines the abortion

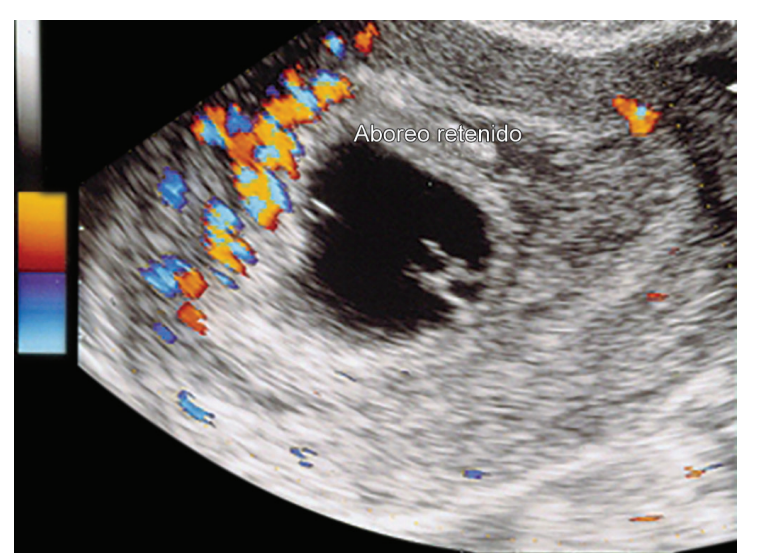

Fig. 22: The use of transvaginal colour Doppler is not helpful for predicting pregnancy outcome in cases of threatened abortion

pregnancies. The PI of the uterine artery was higher in the abortions than in the normal pregnancies. Differences were not observed in RI and systolic peak of the uterine artery, neither in PI or RI of spiral arteries among abortions and normal. This author concludes that the velocity of abnormal flow found in some complicated pregnancies with embryonic death would be related with a defective placentation and "dislocation" of the trophoblastic wall, to which the embryonic death follows. The premature access of maternal blood to the intervillous space would break the embryonic-maternal interface, and would be the cause that probably determines abortion (Fig. 20). Alcázar and Ruiz-Perez ${ }^{68}$ communicate that no apparent alteration occurs in the early uteroplacental circulation in patients with threatened abortion with a living embryo so the use of transvaginal color Doppler ultrasound is not helpful for predicting pregnancy outcome in cases of threatened abortion (Fig. 21).

Ozkaya et $\mathrm{al}^{69}$ did a research including 105 patients and measured their RI and PI of uterine arteries, arcuate 
artery, radial artery, and spiral artery. Only 16 patients had an adverse result, where there were 3 cases of spontaneous abortion and 3 other cases of missed abortion. The only Doppler parameter that had a significant difference was the PI and RI in the right uterine artery, which were higher (Fig. 22).

Salim et $\mathrm{al}^{70}$ measured PI and RI at the level of the corpus luteum. The pregnancies with threatened abortion or ending in abortion show higher values than normal pregnancies. However, they don't observe differences when comparing data of ectopic pregnancies, hydatidiform moles, or anembryonic pregnancies.

Alcázar et $\mathrm{al}^{71}$ measured the flows at the level of the corpus luteum, not finding differences among controls, abortion threat, or blighted ovum. In pregnancies with confirmed abortion, the values of RI are higher.

\section{Other Factors to Consider (Clinical Nature)}

- Maternal age: Above 35 to 40 years

- Presence of uterine bleeding

- Moment of beginning of uterine bleeding

- Hormonal dynamics determination ( $\beta$-hCG)

- Reproductive antecedents (one or more previous abortions)

- Existence of associate pathology (multiple or submucous myomas), uterine malformations

- First-trimester chorionic bumps: Sana et $\mathrm{al}^{72}$ report that women presenting to early pregnancy units with a chorionic bump discovered at 1st trimester ultrasound examination had approximately double the risk of miscarriage compared with matched controls, the difference being due to a greater number of miscarriages during the second trimester of pregnancy. Harris et al ${ }^{73}$ also investigated a series of cases comparing on the one hand those with chorionic bumps and on the contrary those without them, and there were seen statistically significant differences in the outcome of the pregnancy being worse for the chorionic bump group.

\section{REFERENCES}

1. Barri PN. Pérdidas embrionarias preimplantatorias. In: Carrera JM, Kurjak A, editors. Medicina del embrión. Barcelona: Masson; 1996. p. 143-148.

2. Leridon H. Human fertility. Chicago: Chicago Press; 1977.

3. De la Fuente, P. Aborto espontáneo. In: Fabre E, editor. Manual de Asistencia a la Patología Obstétrica. Zaragoza: INO Reproducciones; 1997. p. 73-87.

4. Knudsen UB, Hansen V, Juul S, Secher NJ. Prognosis of a new pregnancy following previous spontaneous abortions. Eur J Obstet Gynecol Reprod Biol 1991 Mar;39(1):31-36.

5. Cashner KA, Christopher CR, Dysert GA. Spontaneous fetal loss after demonstration of a live fetus in the first trimester. Obstet Gynecol 1987 Dec;70(6):827-830.
6. Rempen A. The incidence of abortions of viable pregnancies in the first trimester. Zentralbl Gynakol 1993;115(6):249-257.

7. Siddiqi TA, Caligaris JT, Miodovnik M, Holroyde JC, Mimouni F. Rate of spontaneous abortion after first trimester sonographic demonstration of fetal cardiac activity. Am J Perinatol 1988 Jan;5(1):1-4.

8. Levi CS, Lyons EA, Zheng XH, Lindsay DJ, Holt SC. Endovaginal US: demonstration of cardiac activity in embryos of less than $5.0 \mathrm{~mm}$ in crown-rump length. Radiology 1990 Jul;176(1):71-74.

9. Goldstein SR. Embryonic death in early pregnancy: a new look at the first trimester. Obstet Gynecol 1994 Aug;84(2): 294-297.

10. Philipp T, Philipp K, Reiner A, Beer F, Kalousek DK. Embryoscopic and cytogenetic analysis of 233 missed abortions: factors involved in the pathogenesis of developmental defects of early failed pregnancies. Hum Reprod 2003 Aug;18(8):1724-1732.

11. Hartge DR, Schröer A, Weichert J. Novel insights into early embryonic demise via 3D surface rendered imaging in 107 cases. Ultraschall Med 2015 Feb;36(1):47-53.

12. Connolly A, Ryan DH, Stuebe AM, Wolfe HM. Reevaluation of discriminatory and threshold levels for serum $\beta$-hCG in early pregnancy. Obstet Gynecol 2013 Jan;121(1):65-70.

13. Goldstein SR. Significance of cardiac activity on endovaginal ultrasound in very early embryos. Obstet Gynecol 1992 Oct;80(4):670-672.

14. Committee on Practice Bulletins - Gynecology. The American College of Obstetricians and Gynecologists Practice Bulletin no. 150. Early pregnancy loss. Obstet Gynecol 2015 May;125(5): 1258-1267.

15. Abdallah Y, Daemen A, Kirk E, Pexsters A, Naji O, Stalder C, Gould D, Ahmed S, Guha S, Syed S, et al. Limitations of current definitions of miscarriage using mean gestational sac diameter and crown-rump length measurements: a multicenter observational study. Ultrasound Obstet Gynecol 2011 Nov;38(5):497-502.

16. Abdallah Y, Daemen A, Guha S, Syed S, Naji O, Pexsters A, Kirk E, Stalder C, Gould D, Ahmed S, et al. Gestational sac and embryonic growth are not useful as criteria to define miscarriage: a multicenter observational study. Ultrasound Obstet Gynecol 2011 Nov;38(5):503-509.

17. Jeve Y, Rana R, Bhide A, Thangaratinam S. Accuracy of firsttrimester ultrasound in the diagnosis of early embryonic demise: a systematic review. Ultrasound Obstet Gynecol 2011 Nov;38(5):489-496.

18. Ectopic pregnancy and miscarriage: diagnosis and initial management in early pregnancy of ectopic pregnancy and miscarriage. London: National Institute for Health and Care Excellence; 2012.

19. Preisler J, Kopeika J, Ismail L, Vathanan V, Farren J, Abdallah Y, Battacharjee P, Van Holsbeke C, Bottomley C, Gould D, et al. Defining safe criteria to diagnose miscarriage: prospective observational multicentre study. BMJ 2015 Sep;351:h4579.

20. Daya S, Woods S, Ward S, Lappalainen R, Caco C. Early pregnancy assessment with transvaginal ultrasound scanning. CMAJ 1991 Feb;144(4):441-446.

21. Goldstein I, Zimmer EA, Tamir A, Peretz BA, Paldi E. Evaluation of normal gestational sac growth: appearance of embryonic heartbeat and embryo body movements using the transvaginal technique. Obstet Gynecol 1991 Jun;77(6):885-888. 
22. Cho FN, Chen SN, Tai MH, Yang TL. The quality and size of yolk sac in early pregnancy loss. Aust N Z J Obstet Gynaecol 2006 Oct; $46(5): 413-418$.

23. Hernadi L, Torocsik M, Farkas M. Significance of transvaginal ultrasonic examination in the first pregnancy trimester. Orv Hetil 1990 Dec;131(49):2687-2691.

24. Brown DL, Emerson DS, Felker RE, Cartier MS, Smith WC. Diagnosis of early embryonic demise by endovaginal sonography. J Ultrasound Med 1990 Nov;9(11):631-636.

25. Bernard KG, Cooperberg PL. Sonographic differentiation between blighted ovum and early viable pregnancy. AJR Am J Roentgenol 1985 Mar;144(3):597-602.

26. Nyberg DA, Mack LA, Laing FC, Patten RM. Distinguishing normal from abnormal gestational sac growth in early pregnancy. J Ultrasound Med 1987 Jan;6(1):23-27.

27. Perriera L, Reeves MF. Ultrasound criteria for diagnosis of early pregnancy failure and ectopic pregnancy. Semin Reprod Med 2008 Sep;26(5):373-382.

28. McKenna KM, Feldstein VA, Goldstein RB, Filly RA. The empty amnion: a sign of early pregnancy failure. J Ultrasound Med 1995 Feb;14(2):117-121.

29. Stamatopoulos N, Lu C, Casikar I, Reid S, Mongelli M, Hardy N, Condous G. Prediction of subsequent miscarriage risk in women who present with a viable pregnancy at the first early pregnancy scan. Aust N Z J Obstet Gynaecol 2015 Oct;55(5):464-472.

30. Bromley B, Harlow BL, Laboda LA, Benacerraf BR. Small sac size in the first trimester: a predictor of poor fetal outcome. Radiology 1991 Feb;178(2):375-377.

31. Dickey RP, Olar TT, Taylor SN, Curole DN, Matulich EM. Relationship of small gestational sac-crown-rump length differences to abortion and abortus karyotypes. Obstet Gynecol 1992 Apr;79(4):554-557.

32. Filly RA. The first trimester. In: Peter W, editor. Sonography in obstetrics and gynecology. Buenos Aires: Pan-American; 1991. p. 35-61.

33. Merchiers EH, Dhont M, De Sutter PA, Beghin CJ, Vandekerckhove DA. Predictive value of early embryonic cardiac activity for pregnancy outcome. Am J Obstet Gynecol 1991 Jul;165(1):11-14.

34. Laboda LA, Estroff JA, Benacerraf BR. First trimester bradycardia. A sign of impending fetal loss. J Ultrasound Med 1989 Oct;8(10):561-563.

35. May DA, Sturtevant NV. Embryonal heart rate as a predictor of pregnancy outcome: a prospective analysis. J Ultrasound Med 1991 Oct;10(10):591-593.

36. Benson S, Doubilet PM. Slow embryonic heart rate in early first trimester: indicator of poor pregnancy outcome. Radiology 1994 Aug;192(2):343-344.

37. Doubilet PM, Benson CB. Embryonic heart rate in the early first trimester: What rate is normal? J Ultrasound Med 1995 Jun;14(6):431-434.

38. Stefos TI, Lolis DE, Sotiriadis AJ, Ziakas GV. Embryonic heart rate in early pregnancy. J Clin Ultrasound 1998 Jan;26(1): 33-36.

39. Cepni I, Bese T, Ocal P, Budak E, Idil M, Aksu MF. Significance of yolk sac measurements with vaginal sonography in the first trimester in the prediction of pregnancy outcome. Acta Obstet Gynecol Scand 1997 Nov;76(10):969-972.

40. Küçük T, Duru NK, Yenen MC, Dede M, Ergün A, Başer I. Yolk sac size and shape as predictors of poor pregnancy outcome. J Perinat Med 1999;27(4):316-320.
41. Stampone C, Nicotra M, Muttinelli C, Cosmi EV. Transvaginal sonography of the yolk sac in normal and abnormal pregnancy. J Clin Ultrasound 1996 Jan;24(1):3-9.

42. Lindsay DJ, Lovett IS, Lyons EA, Levi CS, Zheng XH, Holt SC, Dashefsky SM. Yolk sac diameter and shape at endovaginal US: predictors of pregnancy outcome in the first trimester. Radiology 1992 Apr;183(1):115-118.

43. Kupesic S, Kurjak A. Volume and vascularity of the yolk sac assessed by three-dimensional and power Doppler ultrasound. Early Pregnancy 2001 Jan;5(1):40-41.

44. Iniesta S, Pérez-Medina T, Redondo T, Bajo JM. Alteración ecográfica del saco vitelino como predictor de mal pronóstico de la gestación. Toko Gin Prakt 2004;674:151-154.

45. Filly MR, Callen PW, Yegul NT, Filly RA. The yolk stalk sign: evidence of death in small embryos without heartbeats. J Ultrasound Med 2010 Feb;29(2):237-241.

46. Bajo J, Moreno-Calvo FJ, Martinez-Cortés L, Haya FJ, Rayward J. Is trophoblastic thickness at the embryonic implantation site a new sign of negative evolution in first trimester pregnancy? Hum Reprod 2000 Jul;15(7):1629-1631.

47. Dickey RP, Olar TT, Curole DN, Taylor SN, Matulich EM. Relationship of first-trimester subchorionic bleeding detected by color Doppler ultrasound to subchorionic flows, clinical bleeding, and pregnancy outcome. Obstet Gynecol 1992 Sep;80 (3 Pt 2):415-420.

48. Stabile I, Campbell S, Grudzinskas JG. Threatened miscarriage and intrauterine hematomas. Sonographic and biochemical studies. J Ultrasound Med 1989 Jun;8(6):289-292.

49. Glavind K, Nøhr S, Nielsen PH, Ipsen L. Intra-uterine hematoma in pregnancy. Eur J Obstet Gynecol Reprod Biol 1991 Jun;40(1):7-10.

50. Kurjak A, Schulman H, Zudenigo D, Kupesic S, Kos M, Goldenberg M. Subchorionic hematomas in early pregnancy: clinical outcome and blood flow patterns. J Matern Fetal Med 1996 Jan-Feb;5(1):41-44.

51. Kurjak A, Zalud I, Predanic M, Kupesic S. Transvaginal color and pulsed Doppler study of uterine blood flow in the first and early second trimesters of pregnancy: normal versus abnormal. J Ultrasound Med 1994 Jan;13(1):43-47.

52. Ball RH, Ade CM, Schoenborn JA, Crane JP. The clinical significance of ultrasonographically detected subchorionic hemorrhages. Am J Obstet Gynecol 1996 Mar;174(3):996-1002.

53. Bennett GL, Bromley B, Lieberman E, Benacerraf BR. Subchorionic hemorrhage in first-trimester pregnancies: prediction of pregnancy outcome with sonography. Radiology 1996 Sep;200(3):803-806.

54. Johns J, Hyett J, Jauniaux E. Obstetric outcome after threatened miscarriage with and without a hematoma on ultrasound. Obstet Gynecol 2003 Sep;102(3):483-487.

55. Nagy S, Bush M, Stone J, Lapinski RH, Gardó S. Clinical significance of subchorionic and retroplacental hematomas detected in the first trimester of pregnancy. Obstet Gynecol 2003 Jul;102(1):94-100.

56. Poulose T, Richardson R, Ewings P, Fox R. Probability of early pregnancy loss in women with vaginal bleeding and a singleton live fetus at ultrasound scan. J Obstet Gynaecol 2006 Nov;26(8):782-784

57. Koornstra G, Exalto N. Echography in the first pregnancy trimester has prognostic value. Ned Tijdschr Geneeskd 1991 Nov;135(47):2231-2235.

58. Leelapatana P, Garrett WJ, Warren PS. Early growth retardation in the first trimester: is it characteristic of the 
chromosomally abnormal fetus? Aust N Z J Obstet Gynaecol 1992 May;32(2):95-97.

59. Bessho T, Sakamoto H, Shiotani T, Komori S, Koyama K. Fetal loss in the first trimester after demonstration of cardiac activity: relation of cytogenetic and ultrasound findings. Hum Reprod 1995 Oct;10(10):2696-2699.

60. Coulam CB, Goodman C, Dorfmann A. Comparison of ultrasonographic findings in spontaneous abortions with normal and abnormal karyotypes. Hum Reprod 1997 Apr;12(4): 823-826.

61. Anderson SG. Management of threatened abortion with real-time sonography. Obstet Gynecol 1980 Feb;55(2): 259-262.

62. Kurjak A, Kupesic S. Doppler assessment of the intervillous blood flow in normal and abnormal early pregnancy. Obstet Gynecol 1997 Feb;89(2):252-256.

63. Jaffe R, Jauniaux E, Hustin J. Maternal circulation in the firsttrimester human placenta - myth or reality? Am J Obstet Gynecol 1997 Mar;176(3):695-705.

64. Jaffe R, Woods JR. Doppler velocimetry of intraplacental fetal vessels in the second trimester: improving the prediction of pregnancy complications in high-risk patients. Ultrasound Obstet Gynecol 1996 Oct;8(4):262-266.

65. Mercé LT, Barco MJ, Bau S. Color Doppler sonographic assessment of placental circulation in the first trimester of normal pregnancy. J Ultrasound Med 1996 Feb;15(2):135-142.

66. Kurjak A, Kupesic S. Parallel Doppler assessment of yolk sac and intervillous circulation in normal pregnancy and missed abortion. Placenta 1998 Nov;19(8):619-623.

67. Jauniaux E, Johnson MR, Jurkovic D, Ramsay B, Campbell S, Meuris S. The role of relaxin in the development of the uteroplacental circulation in early pregnancy. Obstet Gynecol 1994 Sep;84(3):338-342.

68. Alcázar JL, Ruiz-Perez ML. Uteroplacental circulation in patients with first-trimester threatened abortion. Fertil Steril 2000 Jan;73(1):130-135.

69. Ozkaya U, Ozkan S, Ozeren S, Corakçi A. Doppler examination of uteroplacental circulation in early pregnancy: can it predict adverse outcome? J Clin Ultrasound 2007 Sep;35(7):382-386.

70. Salim A, Zalud I, Farmakides G, Schulman H, Kurjak A, Latin V. Corpus luteum blood flow in normal and abnormal early pregnancy: evaluation with transvaginal color and pulsed Doppler sonography. J Ultrasound Med 1994 Dec;13(12):971-975.

71. Alcázar JL, Laparte C, López-Garcia G. Corpus luteum blood flow in abnormal early pregnancy. J Ultrasound Med 1996 Sep;15(9):645-649.

72. Sana Y, Appiah A, Davison A, Nicolaides KH, Johns J, Ross JA. Clinical significance of first-trimester chorionic bumps: a matched case-control study. Ultrasound Obstet Gynecol 2013 Nov;42(5):585-589.

73. Harris RD, Couto C, Karpovsky C, Porter MM, Ouhilal S. The chorionic bump: a first-trimester pregnancy sonographic finding associated with a guarded prognosis. J Ultrasound Med 2006 Jun;25(6):757-763.

74. Doubilet PM, Benson CB, Bourne T, Blaivas M, Society of Radiologists in Ultrasound Multispecialty Panel on Early First Trimester Diagnosis of Miscarriage and Exclusion of a Viable Intrauterine Pregnancy, Barnhart KT, Benacerraf BR, Brown DL, Filly RA, Fox JC, et al. Diagnostic criteria for nonviable pregnancy early in the first trimester. N Engl J Med 2013 Oct;369(15):1443-1451. 